\title{
Low birth weight is associated with increased fat intake in school-aged boys
}

\author{
Adrianne R. Bischoff ${ }^{1}$, André K. Portella ${ }^{2 *}$, Catherine Paquet ${ }^{3}$, Roberta Dalle Molle ${ }^{4}$, Aida Faber ${ }^{2}$, \\ Narendra Arora ${ }^{5}$, Robert D. Levitan ${ }^{6,7}$, Patrícia P. Silveira ${ }^{8}$ and Laurette Dube ${ }^{2}$ \\ ${ }^{1}$ Department of Pediatrics, Division of Neonatology, Hospital for Sick Children, University of Toronto, Toronto, ON, M5G $1 X 8$, \\ Canada \\ ${ }^{2}$ McGill Center for the Convergence of Health and Economics, Desautels Faculty of Management, McGill University, Montreal, \\ QC, H3A 1G5, Canada \\ ${ }^{3}$ School of Health Sciences, Centre for Population Health Research, University of South Australia, Adelaide, SA 5001, Australia \\ ${ }^{4}$ Programa de Pós-Graduação em Saúde da Criança e do Adolescente, Faculdade de Medicina, Universidade Federal do Rio \\ Grande do Sul, Porto Alegre, RS, 90035003, Brazil \\ ${ }^{5}$ The INCLEN Trust, New Delhi, 110020, India \\ ${ }^{6}$ Institute of Medical Science, University of Toronto, ON, M5S 1A8, Canada \\ ${ }^{7}$ Centre for Addition and Mental Health (CAMH), Toronto, ON, MOJ 1H4, Canada \\ ${ }^{8}$ Department of Psychiatry, McGill University, Montreal, QC, H3A 1A1, Canada
}

(Submitted 4 August 2017 - Final revision received 8 February 2018 - Accepted 12 March 2018)

\section{Abstract}

Evidence suggests that both high and low birth weight children have increased the risk for obesity and the metabolic syndrome in adulthood. Previously we have found altered feeding behaviour and food preferences in pre-school children and adults born with low birth weight. In this study, we investigated if birth weight was associated with different intake of fat, carbohydrate and/or protein at 6-12 years of age. This is a cross-sectional study where 255 guardians answered online and telephone questions including anthropometrics and demographic data, parental family food rules (food control, encouragement and restriction) and a complete web-based FFQ for their children (130 boys and 125 girls). Baseline demographic and parental food rules characteristics did not differ accordingly to sex. Linear regression models were conducted separately for each sex, adjusted for income, age and maternal age. There were no differences in total energy intake, but energy density (ED, energy content $/ \mathrm{g}$ ) was negatively associated with birth weight in boys. Macronutrient analysis showed that ED intake was from a greater intake of fat. Birth weight was not a significant predictor of protein and carbohydrate intake in boys. In girls, we saw a positive correlation between fat intake and cholesterol intake $v$. birth weight, but no association with ED intake (results did not remain after adjustment). The study shows that low birth weight is associated with altered fat intake in childhood in a sex-specific manner. It is likely that biological factors such as fetal programming of homoeostatic and/or hedonic pathways influencing food preferences are involved in this process

Key words: Birth weight: Parental food rules: Fat preference: Thrifty eating phenotype: Thrifty phenotype

The relationship between birth weight and the development of chronic non-communicable diseases (NCD) in adult life has been well established. This association, called the Thrifty Phenotype Hypothesis, was developed by David Barker and others ${ }^{(1-4)}$ and stipulates that children born with low birth weight, or some degree of growth restriction, have a higher incidence of $\mathrm{CVD}^{(3)}$, type II diabetes mellitus $^{(4)}$ and the metabolic syndrome $e^{(1,2,4)}$ during their life course. The reasons why intra-uterine growth restriction (IUGR) is linked to many adverse life conditions involves, amongst others, a series of biochemical, hormonal and structural alterations. The combination of such alterations put the individual on a different life course trajectory, with an increased risk for NCD, in a process called programming ${ }^{(5)}$. On the other spectrum of birth weight, being born large for gestational age is also associated with such higher risk for obesity and metabolic disease ${ }^{(6-8)}$, a process believed to be secondary to fetal overnutrition, early fat retention and known as the Pederson Hypothesis ${ }^{(9)}$.

Children's eating behaviour is modulated by a variety of factors that range from genetic to environmental influences $^{(10,11)}$. Parental behaviour including feeding practices, parental response to infant temperament and parental perception of infant growth and appetite are important mediators and modulators of infant feeding behaviour ${ }^{(12)}$. Therefore, understanding the factors that contribute to the development of unhealthy eating behaviours is an important step into promoting a healthier life trajectory.

Abbreviations: BWR, birth weight ratio; IUGR, intra-uterine growth restriction.

* Corresponding author: A. K. Portella, email akportella@gmail.com 
In many instances, we and others have found evidence for a behavioural compound to the Thrifty Phenotype Hypothesis, suggesting altered feeding preferences in low birth weight individuals. However, until now, the literature on the association between birth weight and its behavioural compounds has been sparse at best, and with results that vary accordingly to age and sex investigated. Nevertheless, results always favour the intake of foods either rich in sugar ${ }^{(13,14)}$ or fat (i.e. foods with higher energetic density), when compared with individuals with normal birth weight ${ }^{(15,16)}$. We refer to it as the Thrifty Eating Phenotype Hypothesis ${ }^{(17,18)}$, and to our knowledge, there is no evidence documenting the association between IUGR and preference for certain macronutrients in children aged $6-12$ years.

Therefore, in this study, we investigated if birth weight is associated with increased energy intake and/or increased preference for carbohydrate, protein, or fat at 6-12 years of age. We aim to provide an important piece of evidence by helping to understand how behavioural, physiological and developmental mechanisms interact in school-aged children to affect the programming of health and disease.

\section{Methods}

A sample of households from the Montreal Metropolitan area was selected from a larger database of families who previously indicated their willingness to partake in academic research and were likely to have children in the target age group (6-12 years old). These families were contacted by telephone by an independent research firm (SM Research) and invited to take part in a survey about children's eating and lifestyle habits on behalf of researchers from McGill University. This survey was part one of the multi-component Brain-to-Society diagnostic study aiming to map children's behaviours regarding a multitude of factors, including their environment, eating habits, physical activity and BMI. Given the wide scope of the research programme and the more limited cognitive capacity of children, questionnaires were completed by children's parents or guardians.

Respondents were first asked whether there were any children aged 6-12 years who lived in their households most of the time. If yes, the interviewer then proceeded to ask to speak with the parent or guardian who knew the child's daily habits best. If more than one child between 6 and 12 years old was residing in the household, the parent/guardian was asked to answer all questions regarding the child who had the next birthday. Verbal consent was obtained from all participants, who were mailed a $\$ 10$ check for completing the 50-min telephonic survey including household demographic information, children's anthropometrics (height and weight), physical activities and information about birth weight and gestational age at birth. Data collection took place between March and August 2013. Verbal consent was obtained from all participants included in the study, and ethical approval was obtained from McGill University's Institutional Research Board. All procedures performed in studies involving human participants were in accordance with the ethical standards of the institutional and/or national research committee and with the 1964 Helsinki declaration and its later amendments or comparable ethical standards. The overall response rate for the telephone interview was $23 \%$. (Fig. 1).

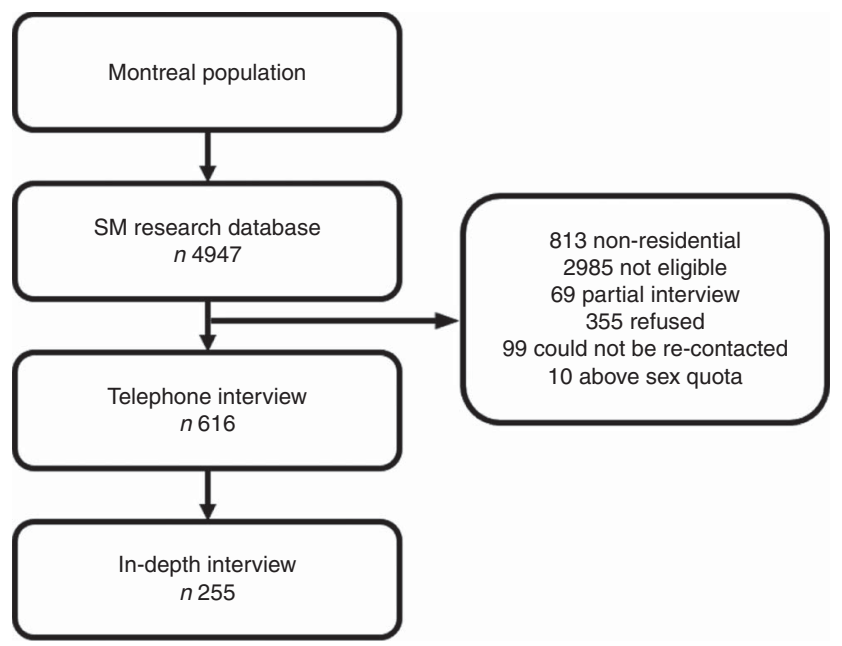

Fig. 1. Flow chart of study participants included in the analysis.

Participants who completed the telephone interview were then invited to complete a follow-up self-administered questionnaire. Participants who agreed were mailed the questionnaire and, as part of the process, completed a consent (parent) and assent (child) form and mailed the forms and completed questionnaires back to the investigators using a pre-stamped envelope. The sample for this study consists of children of parents who completed both the telephone and self-administered parts ( $n$ 255).

The survey included a web-based FFQ to assess children's eating patterns, validated by Labonte et al., designed and validated for the Quebec population ${ }^{(19)}$. Participants were required to recall their children's food intake over the last month based on a list of 136 individual food items or food clusters. These items covered eight categories of food and beverages: dairy products, vegetables, fruits, meat and alternatives, beverages, cereal and grain products, 'other foods' and supplements. For each individual item, participants had to indicate the frequency of consumption from 'never' to 'four or more times per day'. Parents estimated portion sizes using the visual aid of digital photos representing the food in standardised dinnerware and utensils based on the SU. VI. MAX food atlas ${ }^{(20)}$. The survey integrated parent-reported frequency and portion size of each food with nutrients values, based on the Nutrition Data System for Research ${ }^{(21)}$ and the Canadian Nutrient file ${ }^{(22)}$, to calculate the energy content (energy content), total intake (in g) of lipids (fats), proteins and carbohydrates, as well as fibres and cholesterol. The analysis of each macronutrient was conducted by evaluating its crude, unadjusted value, and also by normalising to total intake in grams, in energy content and by the residual method ${ }^{(23)}$ as suggested by Willett et al. ${ }^{(23)}$. The use of these multiple methods is to ensure that the analysis is not impaired by co-linearity issues and confounding by total energy intake.

The Food Rules questionnaire ${ }^{(24)}$ was used to assess parental control, encouragement and restriction rules related to food. Parents answered how often they remember being reinforced for certain rules about food on their childhood, on a scale from 1 (never) to 5 (very often). The control rules subscale 
included four items on how often the parent used food as reinforcement or punishment for their children's behaviour (Cronbach's $\alpha=0.65$ ). The subscale of restriction rules included eight questions about how often they restricted consumption of certain foods to their children (Cronbach's $\alpha=0 \cdot 76$ ). The encouragement rules included eight items about the frequency of parents promoting or encouraging child food intake, overriding satiety signals (Cronbach's $\alpha=0.79$ ).

\section{Statistical methods}

Birth weight was normalised to average Canadian gestational birth weight for gestational age (birth weight ratio (BWR) $)^{(25)}$, in order to more accurately represent adequateness of birth weight to the respective gestational age, sex and populational standards. Variables were described as means and standard deviations, medians and interquartile ranges or numbers and percentages. Nutrient intake from FFQ analyses was performed separately by sex, because of documented differences in eating behaviour between sexes ${ }^{(26)}$, and was tested for sex $v$. BWR interaction. Linear regression models were used to evaluate the influence of BWR on nutrient intake (percentage of total energetic intake, residual method and total weight including fibres), and food rules (food restriction, encouragement and control rules). The first model tested unadjusted associations between BWR and the dependent variables and a second model adjusted

Table 1. Descriptive table of sample characteristics $(n 255)^{*}$

(Mean values and standard deviations; medians and interquartile ranges (IQR); numbers and percentages)

\begin{tabular}{|c|c|c|c|c|c|c|c|}
\hline & \multicolumn{2}{|c|}{ Total } & \multicolumn{2}{|r|}{ Boys } & \multicolumn{2}{|c|}{ Girls } & \multirow[b]{2}{*}{$P$} \\
\hline & $n$ & $\%$ & $n$ & $\%$ & $n$ & $\%$ & \\
\hline \multicolumn{8}{|l|}{ Characteristics at birth } \\
\hline Birth weight $(\mathrm{kg})$ & & & & & & & 0.993 \\
\hline Mean & \multicolumn{2}{|c|}{3.426} & \multicolumn{2}{|r|}{3.43} & \multicolumn{2}{|c|}{3.43} & \\
\hline SD & \multicolumn{2}{|c|}{0.6} & \multicolumn{2}{|r|}{0.6} & \multicolumn{2}{|c|}{0.6} & \\
\hline Gestational age (weeks) & \multirow{3}{*}{\multicolumn{2}{|c|}{$\begin{array}{c}40 \\
39-41\end{array}$}} & & & & & 0.139 \\
\hline Median & & & \multirow{2}{*}{\multicolumn{2}{|c|}{$\begin{array}{c}39.5 \\
38-40\end{array}$}} & \multirow{2}{*}{\multicolumn{2}{|c|}{40}} & \\
\hline IQR & & & & & & & \\
\hline Prematurity ( $<37$ week GA) & 47 & $18 \cdot 4$ & 25 & $19 \cdot 2$ & 22 & $17 \cdot 6$ & 0.750 \\
\hline BWR & & & & & & & 0.475 \\
\hline Mean & \multirow{2}{*}{\multicolumn{2}{|c|}{$\begin{array}{l}1.02 \\
0.18\end{array}$}} & \multicolumn{2}{|r|}{1.01} & \multicolumn{2}{|c|}{1.03} & \\
\hline SD & & & \multicolumn{2}{|r|}{0.19} & \multicolumn{2}{|c|}{0.17} & \\
\hline Girls & 125 & 49.02 & - & - & - & - & - \\
\hline Maternal age at birth (years) & & & & & & & 0.695 \\
\hline Median & \multirow{2}{*}{\multicolumn{2}{|c|}{$\begin{array}{c}31 \\
28-35\end{array}$}} & \multirow{2}{*}{\multicolumn{2}{|c|}{$\begin{array}{c}32 \\
28 \cdot 75-35\end{array}$}} & \multicolumn{2}{|c|}{31} & \\
\hline IQR & & & & & & & \\
\hline \multicolumn{8}{|l|}{ Characteristics at assessment } \\
\hline House income (Can\$/year) & & & & & & & \\
\hline$<25000$ & 11 & 4.5 & 4 & 3.3 & 7 & $5 \cdot 7$ & - \\
\hline $25000-45000$ & 28 & 11.4 & 16 & $13 \cdot 1$ & 12 & $9 \cdot 8$ & - \\
\hline $45000-65000$ & 45 & $17 \cdot 6$ & 20 & $16 \cdot 4$ & 25 & $20 \cdot 3$ & - \\
\hline $65000-95000$ & 81 & $31 \cdot 8$ & 37 & $30 \cdot 3$ & 34 & $27 \cdot 6$ & - \\
\hline$>95000$ & 90 & $35 \cdot 3$ & 45 & $36 \cdot 9$ & 45 & $36 \cdot 6$ & 0.723 \\
\hline Canadian ethnicity & 217 & $85 \cdot 1$ & 110 & $84 \cdot 6$ & 107 & $85 \cdot 6$ & 0.862 \\
\hline Maternal BMI $\left(\mathrm{kg} / \mathrm{cm}^{2}\right)$ & & & & & & & 0.269 \\
\hline Mean & & & & $25 \cdot 9$ & & & \\
\hline SD & & & & $6 \cdot 0$ & & & \\
\hline Underweight $(<18.5)$ & 9 & 3.6 & 7 & 5.4 & 2 & 1.6 & - \\
\hline Normal weight ( 18.5 to 25.0 ) & 126 & $49 \cdot 8$ & 62 & $47 \cdot 7$ & 64 & $52 \cdot 0$ & - \\
\hline Overweight ( 25.0 to 30.0$)$ & 75 & $29 \cdot 6$ & 36 & $27 \cdot 7$ & 39 & $31 \cdot 7$ & - \\
\hline Obesity $(>30.0)$ & 43 & $17 \cdot 0$ & 25 & $19 \cdot 2$ & 18 & 14.6 & 0.275 \\
\hline Child age (years) & 9 & $8-10$ & 9 & $8-10$ & 9 & $7-10$ & 0.115 \\
\hline Child BMI ( $z$ scores) & & & & & & & $0 \cdot 133$ \\
\hline Mean & & & & 0.78 & & & \\
\hline & & & & 1.6 & & & \\
\hline Thinness $(<-2 z$ scores $)$ & 11 & 4.9 & 2 & 1.7 & 9 & $8 \cdot 2$ & - \\
\hline Normal ( -2 to $1 z$ scores $)$ & 126 & $56 \cdot 0$ & 63 & 54.8 & 63 & $57 \cdot 3$ & - \\
\hline Overweight ( +1 to $+2 z$ scores) & 43 & 19.2 & 25 & $21 \cdot 7$ & 18 & $16 \cdot 4$ & - \\
\hline Obesity $(>+2 z$ scores $)$ & 44 & $19 \cdot 6$ & 24 & $21 \cdot 7$ & 20 & $18 \cdot 2$ & 0.110 \\
\hline & & & & & & & \\
\hline Food rules & Unadjusted & Adjusted & & Unadjusted & Adjusted & & \\
\hline Control & 0.102 & 0.096 & & -0.085 & -0.072 & & \\
\hline Encouragement & 0.029 & 0.033 & & 0.036 & 0.028 & & \\
\hline Restriction & 0.068 & 0.072 & & 0.075 & 0.064 & & \\
\hline
\end{tabular}

${ }^{*} P$ values for $t$ test, Pearson's $x^{2}$ or Mann-Whitney test. 
Table 2. $B$ and $\beta$ coefficients for birth weight ratio in linear regression models, unadjusted (model 1) and adjusted (model 2) for family income, children age and maternal age at childbirth $\dagger$

( $B$ and $\beta$ coefficients with their standard errors)

\begin{tabular}{|c|c|c|c|c|c|c|c|c|c|c|c|c|}
\hline & \multicolumn{6}{|c|}{ Boys } & \multicolumn{6}{|c|}{ Girls } \\
\hline & \multicolumn{3}{|c|}{ Model 1} & \multicolumn{3}{|c|}{ Model 2} & \multicolumn{3}{|c|}{ Model 1} & \multicolumn{3}{|c|}{ Model 2} \\
\hline & $B$ & SE $B$ & $\beta$ & $B$ & SE $B$ & $\beta$ & $B$ & SE $B$ & $\beta$ & $B$ & SE $B$ & $\beta$ \\
\hline \multicolumn{13}{|c|}{ Fat (\% total energy content) } \\
\hline BWR & $-6 \cdot 289$ & $2 \cdot 882$ & $-0.191^{*}$ & -6.005 & 2.857 & $-0.182^{*}$ & 6.499 & 3.086 & $0 \cdot 189^{\star}$ & 6.663 & $3 \cdot 151$ & $0.194^{*}$ \\
\hline Age & & - & & 0.297 & 0.303 & 0.086 & & - & & 0.175 & 0.31 & 0.052 \\
\hline Income & & - & & -0.358 & 0.437 & -0.073 & & - & & 0.051 & 0.427 & 0.011 \\
\hline Mat. age at birth & & - & & -0.178 & 0.11 & $-0 \cdot 145$ & & - & & -0.08 & 0.111 & -0.066 \\
\hline$R^{2}$ & & 0.036 & & & 0.078 & & & 0.036 & & & 0.043 & \\
\hline$F$ & & $4 \cdot 763^{*}$ & & & $2 \cdot 602^{*}$ & & & $4.435^{\star}$ & & & 1.326 & \\
\hline \multicolumn{13}{|c|}{ Carbohydrates (\% total energy content) } \\
\hline BWR & $5 \cdot 321$ & 3.919 & 0.12 & 4.892 & 3.86 & 0.11 & -3.079 & 3.817 & -0.073 & -3.477 & 3.868 & -0.083 \\
\hline Age & & - & & -0.716 & 0.41 & -0.153 & & - & & $-0 \cdot 171$ & 0.381 & -0.042 \\
\hline Income & & - & & 0.166 & 0.591 & 0.025 & & - & & $-0 \cdot 17$ & 0.524 & -0.030 \\
\hline Mat. age at birth & & - & & 0.252 & 0.149 & 0.152 & & - & & 0.21 & 0.136 & 0.143 \\
\hline$R^{2}$ & & 0.014 & & & 0.070 & & & 0.005 & & & 0.029 & \\
\hline$F$ & & 1.843 & & & $2 \cdot 303$ & & & 0.650 & & & 0.866 & \\
\hline \multicolumn{13}{|c|}{ Protein (\% total energy content) } \\
\hline BWR & 2.56 & 1.459 & 0.154 & 2.588 & 1.465 & 0.156 & -0.255 & 1.607 & -0.014 & 0.096 & 1.63 & 0.005 \\
\hline Age & & - & & 0.214 & 0.156 & 0.122 & & - & & -0.059 & 0.161 & -0.034 \\
\hline Income & & - & & -0.098 & 0.224 & -0.04 & & - & & 0.321 & 0.221 & 0.136 \\
\hline Mat. age at birth & & - & & -0.007 & 0.057 & -0.012 & & - & & -0.023 & 0.057 & -0.037 \\
\hline$R^{2}$ & & 0.024 & & & 0.041 & & & 0 & & & 0.021 & \\
\hline$F$ & & 3.08 & & & 1.325 & & & 0.025 & & & 0.635 & \\
\hline
\end{tabular}

* $P<0.05$ with Benjamini-Hochberg multiple testing correction.

$\uparrow$ Macronutrients expressed in percentage of total energy content.

for family income (annual family income in Canadian Dollars imputed data was necessary for income ( $n$ 10, imputed as median value of the full sample $(n \text { 612) })^{(27)}$, children age ${ }^{(28-30)}$ and maternal age at childbirth ${ }^{(31)}$. Additional analyses using ANOVA and BWR expressed in the categorical form (using three categories, having -1 and +1 sD from mean as cutoffs) was conducted to evaluate non-linear associations when needed. Taking into account our a priori hypothesis backed by biological plausibility and previous findings that confer a good pre-test probability, we have used the correction for multiple testing of Benjamini-Hochberg ${ }^{(32)}$, using a false discovery rate of $0 \cdot 25$. Statistical significance was set at $P=0 \cdot 05$. We estimate sensitivity to detect an effect size $\left(f^{2}\right)$ as low as $0 \cdot 06$, for a power of $80 \%$ and $n$ of 130 .

\section{Results}

Birth weight was similar to the Canadian population average for gestational age and sex, noted as the average BWR was close to 1. BMI means and prevalence of overweight were also similar to contemporary research findings in Canada ${ }^{(33,34)}$. The household income, as inferred by Table 1, was probably above the median family annual income of Can $\$ 72240$ for Quebec in $2013^{(35)}$. Table 1 summarises the sample characteristics.

In boys, both unadjusted and adjusted linear regression models performed showed a statistically significant negative association between energy density and BWR, indicating that boys with a lower BWR had higher energy density intake. Individual macronutrient associations, on the other hand, were significant only for fat, as depicted by the statistically significant correlations of fat energetic percentage, residual and density methods (see Table 2, and Fig. 2), which suggests that the higher energetic density intake in boys with lower birth weights originated from fat intake. In girls, however, the results followed an opposite pattern, as shown by the positive, and statistically significant, the association between BWR and fat intake. In accordance with this result in girls, we found a statistically significant positive association between BWR and cholesterol intake, but only in the unadjusted analysis. Results from normalisation to total grams and residual method yielded similar statistical results, providing confidence for lack of confounding and collinearity (Table 3). Interaction analysis confirmed statistically significant interactions between sex and BWR for fat grams, fat percentage, fat residual mean, fat energetic density and cholesterol (data not shown).

\section{Discussion}

In this study, we have found a negative correlation between BWR and energetic density intake in 6-12 years old boys, while - on the opposite - BWR was positively associated with energetic density from fat for girls in an unadjusted model. The energetic density intake in boys was mostly obtained from energy content derived from fat, suggesting an altered preference for this macronutrient. Energetic density is indeed mainly determined by water and fat content ${ }^{(36)}$ and can be considered a correlate of palatability ${ }^{(37,38)}$. Dietary fat intake may also contribute to increased energy intake by its lower 

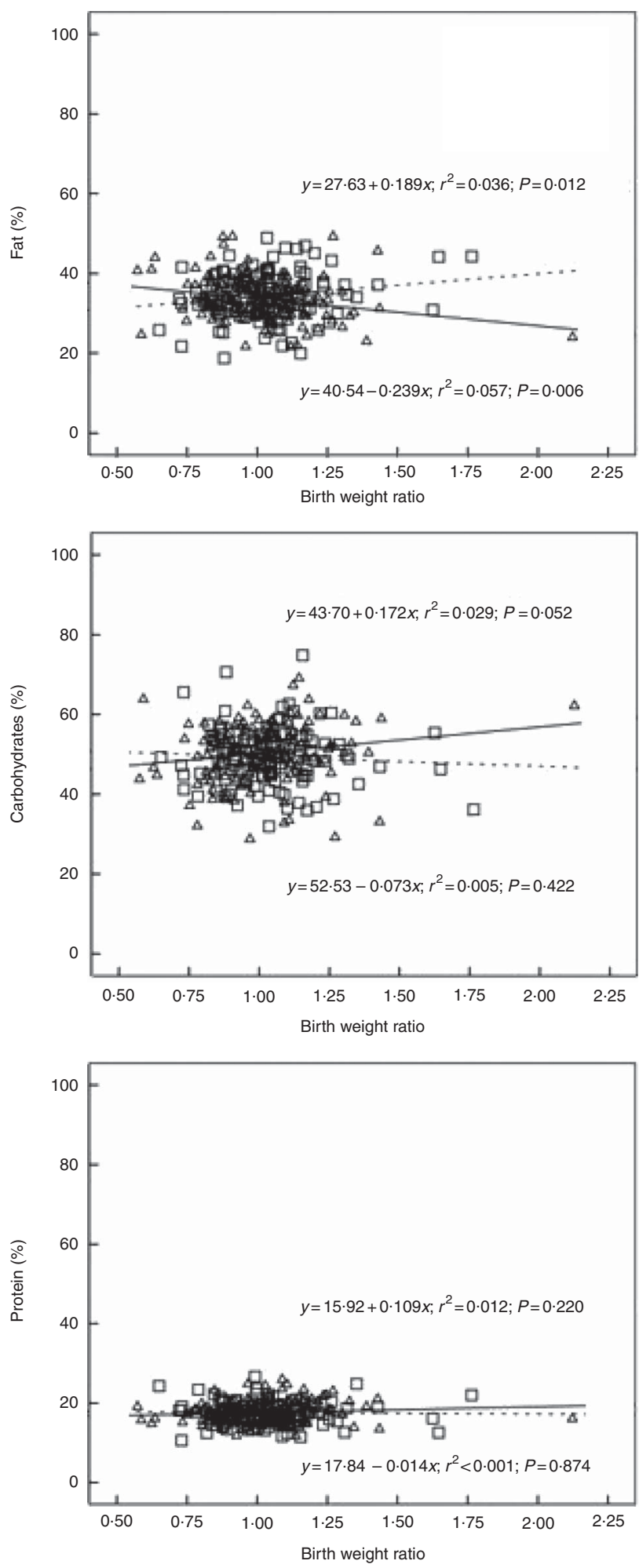

Fig. 2. Scatter plot showing the macronutrients (fat, carbohydrate and protein) intake in the percentage of energy content by total energy intake $v$. birth weight ratio, unadjusted. Regression formula showing unstandardised coefficients, $r^{2}$ effect size and $P$ value. $\Delta$ and $\longrightarrow$, Male; $\square$ and ........, female.

satiety potential ${ }^{(39)}$. Similar findings had already been demonstrated by Crume et al., in a cohort of 506 children with forty-two IUGR children (birth weight below the 15th percentile), in which there was a significantly higher percent energy intake of fat in IUGR children at 10 years of age compared with the unexposed ${ }^{(16)}$. In this study, we confirmed previous findings of increased palatable food intake in a population at risk for the metabolic syndrome. In girls, we found effects suggesting a trend in the opposite direction, indicating that girls with large birth weight are more likely to have higher ingestion of fat. However, this association did not persist after adjustment for confounding variables and when normalised to total energy content or by the residual method.

The biological significance of such effect in terms of cardiovascular risk is difficult to measure. In our case, the BWR range is about 1.5 , representing a spectrum of birth weights from the IUGR (lower BWR $=0.57$ ) to the macrossomic (higher BWR= $2 \cdot 12$ ). In this range of birth weight, we estimated an absolute difference of 9 percentage points of fat intake between those extremes. Alternatively, comparing the IUGR extreme to the mean birth weight, the difference would be an absolute excess of 2.4 points in the percentage of total energetic intake from Fat. In general terms, there is a linear effect of fat intake as measured by the percentage of fat intake into cardiovascular risk ${ }^{(40)}$. In our case, we also need to take into consideration that those with low birth weight are already known to be at increased risk, due to their metabolic programming, and the effect is concentrated in males, which also is a risk factor for CVD ${ }^{(41)}$. This is important because the clustering of risk factors is known to be more deleterious to health than a single factor alone, in both children $^{(42-46)}$ and adults ${ }^{(47,48)}$.

Animal models demonstrate that adversities in the intra-uterine life induce an increased preference for high-fat diets instead of high-protein or high-carbohydrate diets ${ }^{(49-52)}$. The association between IUGR and specific food preferences and feeding behaviour has also been demonstrated in human with some variations among different age groups and sexes. In preterm newborns, for example, the degree of IUGR correlates with pleasurable hedonic responses to sucrose intake in the 1 st day of life ${ }^{(13)}$. In 3-year-old children, one study showed that girls with normal birth weight had a significantly higher ability than boys to delay response to an eating impulse; this relationship was not significant in the IUGR sample, suggesting that IUGR is linked to increased impulsivity towards sweet food rewards ${ }^{(17)}$. Another study with adults revealed higher carbohydrate consumption in women who were severely IUGR at birth $^{(14)}$. Several other studies in adults corroborate the hypothesis that IUGR individuals have a higher preference either towards fats $^{(53-55)}$ or carbohydrates ${ }^{(14)}$. It appears to us that, despite the apparent discrepant food preferences described in different age groups, all studies converge to an increased intake of high energy density foods in IUGR individuals ${ }^{(56)}$. These persistent small nutrient imbalances across lifespan could explain, in part, the increased risk of IUGR developing the metabolic syndrome and other NCD, and could constitute a target for more precise interventions.

Another apparent inconsistency between the different studies that evaluate food preferences according to birth weight is the effect of sex. In general, low birth weight girls/women seem to be more vulnerable to the effects of prenatal programming of food preferences, showing an increased preference for 
Table 3. $\beta$ coefficients for birth weight ratio in linear regression models, unadjusted and adjusted for family income, children age and maternal age at childbirth†

\begin{tabular}{|c|c|c|c|c|c|c|c|c|}
\hline \multirow[b]{3}{*}{ Macronutrients } & \multicolumn{8}{|c|}{$\beta$ standardised coefficients } \\
\hline & \multicolumn{2}{|c|}{ Unnormalised } & \multicolumn{2}{|c|}{$\%$ of Total energy content } & \multicolumn{2}{|c|}{ Residual Method } & \multicolumn{2}{|c|}{ Density (g/total grams) } \\
\hline & Unadjusted & Adjusted & Unadjusted & Adjusted & Unadjusted & Adjusted & Unadjusted & Adjusted \\
\hline \multicolumn{9}{|l|}{ Boys } \\
\hline Fat & -0.103 & -0.096 & $-0.191^{*}$ & $-0.182^{*}$ & $-0.196^{\star}$ & $-0.188^{\star}$ & $-0.185^{*}$ & $-0.176^{*}$ \\
\hline Carbohydrate & -0.014 & -0.012 & 0.120 & 0.110 & 0.107 & 0.097 & 0.082 & 0.073 \\
\hline Protein & 0.015 & 0.020 & 0.154 & 0.156 & 0.176 & 0.178 & 0.094 & 0.100 \\
\hline \multicolumn{9}{|l|}{ Girls } \\
\hline Fat & $0.225^{\star}$ & $0.208^{*}$ & $0.189^{*}$ & 0.194 & 0.209 & 0.209 & 0.156 & 0.158 \\
\hline Carbohydrate & 0.103 & 0.084 & -0.073 & -0.083 & -0.126 & -0.132 & -0.109 & -0.124 \\
\hline Protein & 0.149 & 0.141 & -0.014 & 0.005 & 0.011 & 0.032 & -0.014 & 0.004 \\
\hline
\end{tabular}

${ }^{*} P<0.05$ with Benjamini-Hochberg multiple testing correction.

† Unnormalised: intake in g, absolute value. \% of Total energy content: percentage of total energy content (macronutrient energy content/total energy intake $\times 100)$. Residual method: energy-adjusted intake estimate is the residual from a regression model in which total energy intake is the independent variable and absolute nutrient intake is the dependent variable. Thus, the residual is an estimate of nutrient intake uncorrelated with total energy intake and directly related to overall variation in food choice and composition. Density: intake in $\mathrm{g}$, divided by total intake including fibres.

carbohydrates, impulsivity for sugar and emotional overeating when compared no normal birth weight counterparts ${ }^{(14,17,57)}$. However, other studies do not seem to find a sex effect ${ }^{(54)}$. Boys and girls differ both at the neurological and biological levels, especially in terms of timing (e.g. time of fat rebound, time of puberty, growth patterns, etc. $)^{(58)}$, and these ultimately influence food intake and preferences ${ }^{(59,60)}$. Therefore, while prenatal programming seems to modify eating patterns of both boys and girls when compared with controls, the timing and nature of the differences can vary between the sexes ${ }^{(61)}$, fluctuating according to the adiposity rebound and body fat distribution during development ${ }^{(60)}$. Indeed, in this study, the effect of the fetal programming of food preferences was apparent only in boys, possibly due to the specific age slot of the current investigation. Another aspect to take into consideration in sex differences is that girls may have intrinsic differences for fat and sweet taste from boys ${ }^{(30)}$.

The targeted age for this study is a relevant period because if follows the adiposity rebound ${ }^{(62,63)}$, which is the period in which BMI begins to increase after a nadir, and usually occurs between 5-7 years of age ${ }^{(64-67)}$. Children at this stage have already passed the physiological decrease in appetite that occurs between 1 and 5 years of age ${ }^{(68,69)}$, and are at risk to be obese in adulthood if they are already overweight or obese ${ }^{(70)}$. An early adiposity rebound has been shown to correlate with a variety of outcomes such as body weight gain during infancy ${ }^{(60)}$, metabolic risk $^{(71-73)}$, adiposity in adolescence ${ }^{(65)}$, type 2 diabetes $^{(74)}$ and overweight and obesity ${ }^{(63,64,66)}$. Specifically, type 2 diabetes is associated with small body size at birth, followed by a precocious adiposity rebound ${ }^{(74)}$. Most studies correlate the age of adiposity rebound with size at birth, and it has been shown that small head circumference at birth (a marker of IUGR) is also related to early adiposity rebound ${ }^{(67)}$. Individuals with earlier adiposity rebound have increased levels of leptin at 10 years of age and females have increased adiponectin levels as well ${ }^{(75)}$. Although we did not study pubertal status, it is noteworthy that a significant portion of the population studied might have already entered puberty and this could be a possible confounder, as well as it could explain the sex differences reported, as girls start puberty earlier than boys do. An early adiposity rebound leads to a higher BMI that can also result in earlier pubertal timing ${ }^{(72)}$, which also alters body composition, appetite and metabolic markers.

Our study has some limitations, such as the cross-sectional analysis that limits the assessment to one-time point, the use of a convenience sample, and the use of parent-reported questionnaires. Another aspect is the absence of data on some confounders such as breast-feeding, and family size. Nevertheless, we believe that, despite those limitations that may affect the capacity for causal inference, they do not invalidate our main observation of the association between birth weight and macronutrient intake ${ }^{(76)}$. Moreover, it is important to keep in mind that although our results are in line with previous findings, future research is still needed to better characterise this association, with more adequate and prospective evaluations of food intake and its complex milieu of drivers in order to increase confidence in causative pathways ${ }^{(77,78)}$.

\section{Conclusion}

The study confirms previous findings showing that low birth weight is associated with specific food preferences in a sexspecific manner over the life course. It is, therefore, likely that biological factors such as fetal programming of homoeostatic and/ or hedonic pathways functioning are involved. Awareness of the vulnerability of this group to specific food preferences and behaviours during their life course in conjunction with their increased risk of obesity and related metabolic comorbidities makes birth weight an important element to consider in the clinical practice by providing more careful follow-up during childhood.

\section{Acknowledgements}

This study was funded by the Canadian Institutes of Health Research (CIHR) (CIHR-India grant reference no. INC 110726).

The authors appreciate all organisations' team members involved in this project.

N. A. and L. D. designed the research; L. D. conducted the research; A. R. B., A. K. P., C. P., R. D. M., A. F. and P. P. S. 
analysed data or performed statistical analysis; A. R. B., A. K. P., C. P., R. D. M., A. F., N. A., R. D. L. and P. P. S. wrote the paper; A. R. B., A. K. P., C. P., R. D. M., N. A., R. D. L., P. P. S. and L. D. had primary responsibility for the final content.

The authors declare that there are no conflicts of interest.

\section{References}

1. Hales CN \& Barker DJ (1992) Type 2 (non-insulin-dependent) diabetes mellitus: the thrifty phenotype hypothesis. Diabetologia 35, 595-601.

2. Roseboom TJ, van der Meulen JH, Ravelli AC, et al. (1999) Blood pressure in adults after prenatal exposure to famine. J Hypertens 17, 325-330.

3. Barker DJ, Osmond C, Forsén TJ, et al. (2005) Trajectories of growth among children who have coronary events as adults. $N$ Engl J Med 353, 1802-1809.

4. Eriksson JG, Forsén T, Tuomilehto J, et al. (2002) Effects of size at birth and childhood growth on the insulin resistance syndrome in elderly individuals. Diabetologia 45, 342-348.

5. Lucas A (1991) Programming by early nutrition in man. Ciba Found Symp 156, 38-50; discussion 50-35.

6. Murtaugh MA, Jacobs DR Jr., Moran A, et al. (2003) Relation of birth weight to fasting insulin, insulin resistance, and body size in adolescence. Diabetes Care 26, 187-192.

7. Stansfield BK, Fain ME, Bhatia J, et al. (2016) Nonlinear relationship between birth weight and visceral fat in adolescents. J Pediatr 174, 185-192.

8. Tam CH, Wang Y, Luan J, et al. (2015) Non-linear relationship between birthweight and cardiometabolic risk factors in Chinese adolescents and adults. Diabet Med 32, 220-225.

9. Hadden DR (2008) Prediabetes and the big baby. Diabet Med 25, $1-10$.

10. Scaglioni S, Arrizza C, Vecchi F, et al. (2011) Determinants of children's eating behavior. Am J Clin Nutr 94, 2006S-2011S.

11. Breen FM, Plomin R \& Wardle J (2006) Heritability of food preferences in young children. Physiol Behav 88, 443-447.

12. Faith MS, Van Horn L, Appel LJ, et al. (2012) Evaluating parents and adult caregivers as 'agents of change' for treating obese children: evidence for parent behavior change strategies and research gaps: a scientific statement from the American Heart Association. Circulation 125, 1186-1207.

13. Ayres C, Agranonik M, Portella AK, et al. (2012) Intrauterine growth restriction and the fetal programming of the hedonic response to sweet taste in newborn infants. Int J Pediatr 2012, 657379.

14. Barbieri MA, Portella AK, Silveira PP, et al. (2009) Severe intrauterine growth restriction is associated with higher spontaneous carbohydrate intake in young women. Pediatr Res 65, 215-220.

15. Perala MM, Mannisto S, Kaartinen NE, et al. (2012) Body size at birth is associated with food and nutrient intake in adulthood. PLOS ONE 7, e46139.

16. Crume TL, Scherzinger A, Stamm E, et al. (2014) The longterm impact of intrauterine growth restriction in a diverse U.S. cohort of children: the EPOCH study. Obesity (Silver Spring) 22, 608-615.

17. Silveira PP, Agranonik M, Faras H, et al. (2012) Preliminary evidence for an impulsivity-based thrifty eating phenotype. Pediatr Res 71, 293-298.

18. Reis RS, Dalle Molle R, Machado TD, et al. (2016) Impulsivitybased thrifty eating phenotype and the protective role of $n-3$ PUFAs intake in adolescents. Transl Psychiatry 6, e755.

19. Labonte ME, Cyr A, Baril-Gravel L, et al. (2012) Validity and reproducibility of a web-based, self-administered food frequency questionnaire. Eur J Clin Nutr 66, 166-173.
20. Le Moullec N, Deheeger M, Preziosi P, et al. (1996) Validation du manuel-photos utilisé pour l'enquête alimentaire de l'étude SU.VI.MAX (Validation of the photomanual used for the food survey of the study SU.VI.MAX). Cahiers de nutrition et de diététique 31, 158-164.

21. Schakel SF, Sievert YA \& Buzzard IM (1988) Sources of data for developing and maintaining a nutrient database. J Am Diet Assoc 88, 1268-1271.

22. Health Canada (2016) Canadian nutrient file. www.healthcanada. gc.ca/cnf (accessed September 2016).

23. Willett WC, Howe GR \& Kushi LH (1997) Adjustment for total energy intake in epidemiologic studies. Am J Clin Nutr $\mathbf{6 5}$, 1220S-1228S; discussion 1229S-1231S.

24. Puhl RM \& Schwartz MB (2003) If you are good you can have a cookie: how memories of childhood food rules link to adult eating behaviors. Eat Behav 4, 283-293.

25. Kramer MS, Morin I, Yang H, et al. (2002) Why are babies getting bigger? Temporal trends in fetal growth and its determinants. J Pediatr 141, 538-542.

26. Asarian L \& Geary N (2013) Sex differences in the physiology of eating. Am J Physiol Regul Integr Comp Physiol 305, R1215-R1267.

27. Drewnowski A (2009) Obesity, diets, and social inequalities. Nutr Rev 67, S36-S39.

28. Deglaire A, Mejean C, Castetbon K, et al. (2015) Associations between weight status and liking scores for sweet, salt and fat according to the gender in adults (The Nutrinet-Sante study). Eur J Clin Nutr 69, 40-46.

29. Mennella JA, Finkbeiner S \& Reed DR (2012) The proof is in the pudding: children prefer lower fat but higher sugar than do mothers. Int J Obes (Lond) 36, 1285-1291.

30. Lanfer A, Knof K, Barba G, et al. (2012) Taste preferences in association with dietary habits and weight status in European children: results from the IDEFICS study. Int J Obes (Lond) $\mathbf{3 6}$, $27-34$.

31. Santos LP, Assuncao MC, Matijasevich A, et al. (2016) Dietary intake patterns of children aged 6 years and their association with socioeconomic and demographic characteristics, early feeding practices and body mass index. BMC Public Health 16, 1055

32. Benjamini Y \& Hochberg Y (1995) Controlling the false discovery rate: a practical and powerful approach to multiple testing. J R Stat Soc Series B Stat Methodol 57, 289-300.

33. Kakinami L, Henderson M, Chiolero A, et al. (2014) Identifying the best body mass index metric to assess adiposity change in children. Arch Dis Child 99, 1020-1024.

34. Wicklow B, Becker A, Chateau D, et al. (2015) Comparison of anthropometric measurements in children to predict metabolic syndrome in adolescence: analysis of prospective cohort data. Int J Obes 39, 1070-1078.

35. Statistics Canada (2018) CANSIM. http://www.statcan. gc.ca/tables-tableaux/sum-som/101/cst01/famil108a-eng.htm (accessed January 2018)

36. Blundell JE \& Stubbs RJ (1999) High and low carbohydrate and fat intakes: limits imposed by appetite and palatability and their implications for energy balance. Eur J Clin Nutr 53, Suppl. 1, S148-S165.

37. Drewnowski A (1998) Energy density, palatability, and satiety: implications for weight control. Nutr Rev 56, 347-353.

38. Meiselman HL \& Waterman D (1978) Food preferences of enlisted personnel in the Armed Forces. J Am Diet Assoc 73, 621-629.

39. de Castro JM, Bellisle F, Dalix AM, et al. (2000) Palatability and intake relationships in free-living humans. characterization and independence of influence in North Americans. Physiol Behav 70, 343-350. 
40. Xu J, Eilat-Adar S, Loria C, et al. (2006) Dietary fat intake and risk of coronary heart disease: the Strong Heart Study. Am J Clin Nutr 84, 894-902.

41. Jousilahti P, Vartiainen E, Tuomilehto J, et al. (1999) Sex, age, cardiovascular risk factors, and coronary heart disease: a prospective follow-up study of 14786 middle-aged men and women in Finland. Circulation 99, 1165-1172.

42. Gubbels JS, Kremers SP, Stafleu A, et al. (2012) Clustering of energy balance-related behaviors in 5-year-old children: lifestyle patterns and their longitudinal association with weight status development in early childhood. Int J Behav Nutr Phys Act 9, 77 .

43. Gubbels JS, Kremers SP, Goldbohm RA, et al. (2012) Energy balance-related behavioural patterns in 5-year-old children and the longitudinal association with weight status development in early childhood. Public Health Nutr 15, 1402-1410.

44. Cameron AJ, Crawford DA, Salmon J, et al. (2011) Clustering of obesity-related risk behaviors in children and their mothers. Ann Epidemiol 21, 95-102.

45. Seghers J \& Rutten C (2010) Clustering of multiple lifestyle behaviours and its relationship with weight status and cardiorespiratory fitness in a sample of Flemish 11- to 12-year-olds. Public Health Nutr 13, 1838-1846.

46. Gubbels JS, Kremers SP, Stafleu A, et al. (2009) Clustering of dietary intake and sedentary behavior in 2-year-old children. J Pediatr 155, 194-198.

47. Kremers SPJ, De Bruijn GJ, Schaalma H, et al. (2004) Clustering of energy balance-related behaviours and their intrapersonal determinants. Psychol Health 19, 595-606.

48. Schuit AJ, van Loon AJ, Tijhuis M, et al. (2002) Clustering of lifestyle risk factors in a general adult population. Prev Med 35, 219-224.

49. Bellinger L \& Langley-Evans SC (2005) Fetal programming of appetite by exposure to a maternal low-protein diet in the rat. Clin Sci (Lond) 109, 413-420.

50. Nakashima Y, Tsukita Y \& Yokoyama M (2008) Preferential fat intake of pups nursed by dams fed low fat diet during pregnancy and lactation is higher than that of pups nursed by dams fed control diet and high fat diet. J Nutr Sci Vitaminol (Tokyo) 54, 215-222.

51. Alves MB, Dalle Molle R, Desai M, et al. (2015) Increased palatable food intake and response to food cues in intrauterine growth-restricted rats are related to tyrosine hydroxylase content in the orbitofrontal cortex and nucleus accumbens. Behav Brain Res 287, 73-81.

52. Dalle Molle R, Laureano DP, Alves MB, et al. (2015) Intrauterine growth restriction increases the preference for palatable foods and affects sensitivity to food rewards in male and female adult rats. Brain Res 1618, 41-49.

53. Stein AD, Rundle A, Wada N, et al. (2009) Associations of gestational exposure to famine with energy balance and macronutrient density of the diet at age 58 years differ according to the reference population used. $J$ Nutr 139 , $1555-1561$.

54. Lussana F, Painter RC, Ocke MC, et al. (2008) Prenatal exposure to the Dutch famine is associated with a preference for fatty foods and a more atherogenic lipid profile. Am J Clin Nutr 88, 1648-1652.

55. Perälä MM, Männistö S, Kaartinen NE, et al. (2012) Body size at birth is associated with food and nutrient intake in adulthood. PLOS ONE 7, e46139.

56. Portella AK \& Silveira PP (2014) Neurobehavioral determinants of nutritional security in fetal growth-restricted individuals. Ann N Y Acad Sci 1331, 15-33.

57. Escobar RS, O'Donnell KA, Colalillo S, et al. (2014) Better quality of mother-child interaction at 4 years of age decreases emotional overeating in IUGR girls. Appetite 81, $337-342$.

58. Eisenmann JC, Heelan KA \& Welk GJ (2004) Assessing body composition among 3- to 8-year-old children: anthropometry, BIA, and DXA. Obes Res 12, 1633-1640.

59. de Beer M, Vrijkotte TG, Fall CH, et al. (2015) Associations of infant feeding and timing of linear growth and relative weight gain during early life with childhood body composition. Int $J$ Obes (Lond) 39, 586-592.

60. Koyama S, Sairenchi T, Shimura N, et al. (2015) Association between timing of adiposity rebound and body weight gain during infancy. J Pediatr 166, 309-312.

61. Dulloo AG, Jacquet J, Seydoux J, et al. (2006) The thrifty 'catch-up fat' phenotype: its impact on insulin sensitivity during growth trajectories to obesity and metabolic syndrome. Int J Obes (Lond) 30, Suppl. 4, S23-S35.

62. Rolland-Cachera MF, Deheeger M, Guilloud-Bataille M, et al. (1987) Tracking the development of adiposity from one month of age to adulthood. Ann Hum Biol 14, 219-229.

63. Rolland-Cachera MF, Deheeger M, Maillot M, et al. (2006) Early adiposity rebound: causes and consequences for obesity in children and adults. Int J Obes (Lond) 30, Suppl. 4, S11-S17.

64. Rolland-Cachera MF, Deheeger M, Bellisle F, et al. (1984) Adiposity rebound in children: a simple indicator for predicting obesity. Am J Clin Nutr 39, 129-135.

65. Hughes AR, Sherriff A, Ness AR, et al. (2014) Timing of adiposity rebound and adiposity in adolescence. Pediatrics 134, e1354-e1361.

66. Whitaker RC, Pepe MS, Wright JA, et al. (1998) Early adiposity rebound and the risk of adult obesity. Pediatrics 101, E5.

67. Eriksson JG, Kajantie E, Lampl M, et al. (2014) Small head circumference at birth and early age at adiposity rebound. Acta physiologica 210, 154-160.

68. Leung AK, Marchand V, Sauve RS, et al. (2012) The 'picky eater': the toddler or preschooler who does not eat. Paediatr Child Health 17, 455-460.

69. Leung AK \& Robson WL (1994) The toddler who does not eat. Am Fam Physician 49, 1789-1792, 1799-1800.

70. Whitaker RC, Wright JA, Pepe MS, et al. (1997) Predicting obesity in young adulthood from childhood and parental obesity. N Engl J Med 337, 869-873.

71. Gonzalez L, Corvalan C, Pereira A, et al. (2014) Early adiposity rebound is associated with metabolic risk in 7-year-old children. Int J Obes (Lond) 38, 1299-1304.

72. Koyama S, Ichikawa G, Kojima M, et al. (2014) Adiposity rebound and the development of metabolic syndrome. Pediatrics 133, e114-e119.

73. Peneau S, Gonzalez-Carrascosa R, Gusto G, et al. (2016) Age at adiposity rebound: determinants and association with nutritional status and the metabolic syndrome at adulthood. Int J Obes (Lond) 40, 1150-1156.

74. Eriksson JG, Forsen T, Tuomilehto J, et al. (2003) Early adiposity rebound in childhood and risk of Type 2 diabetes in adult life. Diabetologia 46, 190-194.

75. Flexeder C, Thiering E, Kratzsch J, et al. (2014) Is a child's growth pattern early in life related to serum adipokines at the age of 10 years? Eur J Clin Nutr 68, 25-31.

76. Parrish LA, Marshall JA, Krebs NF, et al. (2003) Validation of a food frequency questionnaire in preschool children. Epidemiology 14, 213-217.

77. Peng RD, Dominici F \& Zeger SL (2006) Reproducible epidemiologic research. Am J Epidemiol 163, 783-789.

78. Pearce N (2013) Global epidemiology: the importance of international comparisons and collaborations. OA Epidemiol 1, 15-19. 